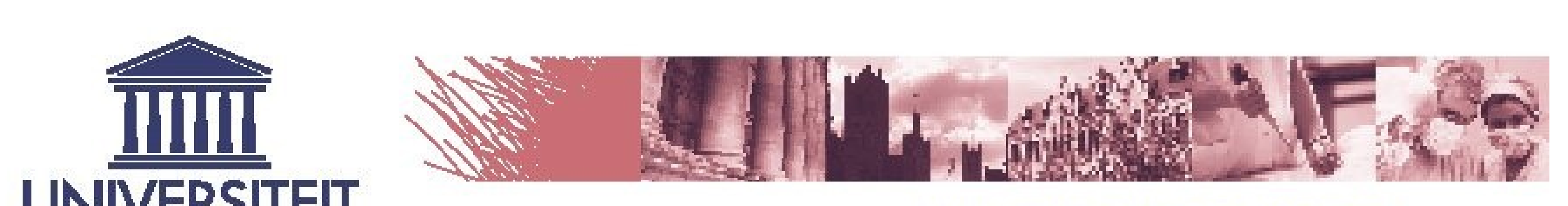

GENT

FACULTEIT GENEESKUNDE EN

GEZONDHEIDSWETENSCHAPPEN

\title{
DEEP VENOUS THROMBOSIS IN BURN PATIENTS: A RETROSPECTIVE ANALYSIS
}

\author{
Fierens J., Hoste E., Benoit D., Monstrey S., Colpaert K. \\ Ghent University Hospital, Burn Unit, Ghent, Belgium
}

\section{Background - Objectives}

Deep venous thrombosis (DVT) is a well-known cause of major morbidity in the surgical patient population. The objective of this retrospective study is to evaluate the incidence of DVT in our burn centre, identify burn-related risk factors as well as risk factors for bacterial surinfection of DVT.

\section{Methods}

All adult burn patients, with a total body surface area (TBSA) more than 10\%, diagnosed with DVT and admitted between 2008 and 2016 in our burn centre were retrospectively evaluated.
The analysis included demographics, location of central lines, number of surgeries, pre-existing medical conditions and inhalation injury. All patients received either routine weightadjusted subcutaneous low-molecular weight heparin (LMWH) prophylaxis or intravenous heparin. A continuous heparin infusion with a targeted activated partial thromboplastin time (aPTT) of 1,5 to 2 times the baseline aPTT value or enoxaparine $0,5 \mathrm{mg} / \mathrm{kg}$ was considered an adequate prophylactic dose of anticoagulant. Patients were matched on age, gender and TBSA with our general burn unit population.

\section{$\underline{\text { Results }}$}

During the study period 611 patients were admitted to the burn unit. 27 patients were diagnosed with DVT (4.4\%) DVT was associated with a inadequate daily dose of prophylactic LMWH $(P<0,01)$. In all patients a central line was located on the DVT location, with a more frequent femoral site $(18 / 27,67 \%)$.

\begin{tabular}{|c|c|c|c|}
\hline \multicolumn{4}{|c|}{ Patient characteristics } \\
\hline & DVT group $(n=27)$ & Control group $(n=27)$ & $P$ - value \\
\hline Age (mean/years) & 51.5 & 51.6 & 0.98 \\
\hline TBSA (mean/\%) & 28.1 & 26,5 & 0.65 \\
\hline Male sex (n (\%)) & $20(74.1)$ & $16(59.3)$ & 0.55 \\
\hline Length of stay (days) (mean (IQR)) & $53.9(11-151)$ & $26.8(1-79)$ & $<0.01$ \\
\hline Mortality (n (\%)) & $1(3.7)$ & $3(11.1)$ & 0.34 \\
\hline Inhalation trauma (n (\%)) & $12(44.4)$ & $6(22.2)$ & 0.15 \\
\hline Pre-existing cardiovascular condition (n (\%)) & $7(25.9)$ & $4(14.8)$ & 0.50 \\
\hline
\end{tabular}
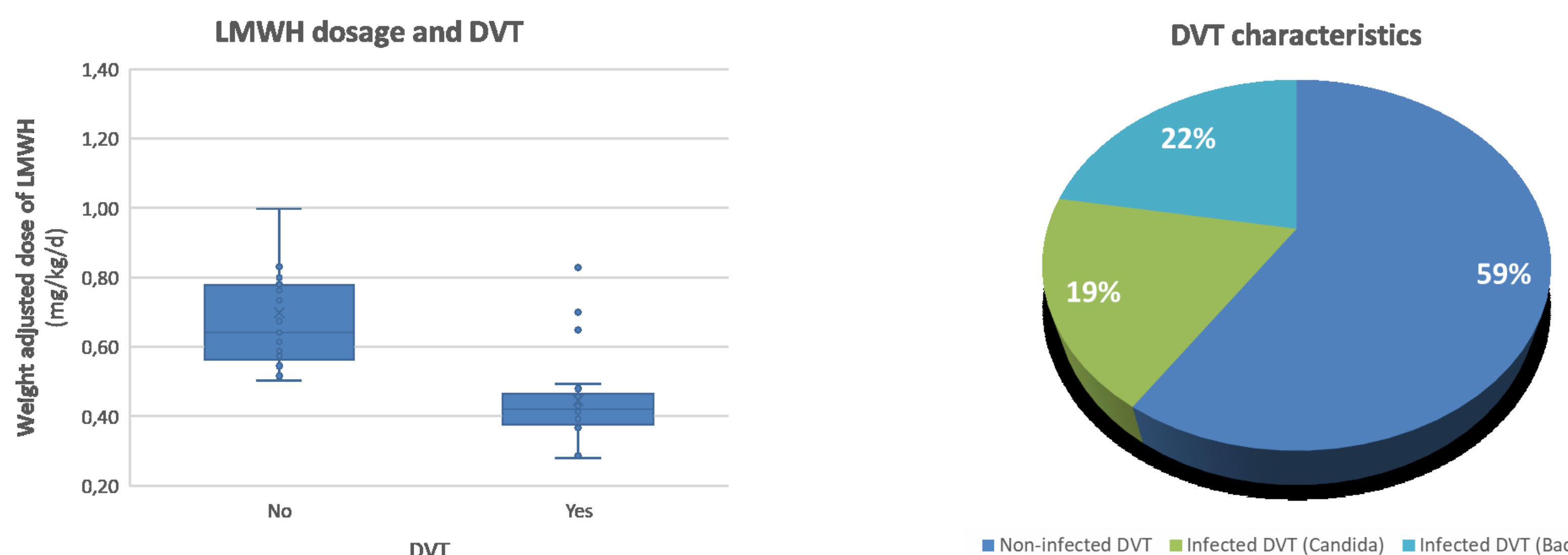

DVT

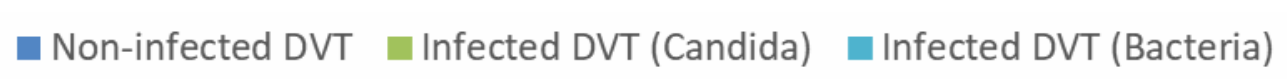

\section{Conclusion}

This study stresses the importance of routine and correctly dosed LMWH administration in burn patients. It highlights the presence of a central line as a major risk factor and the additional hazard of thrombus surinfection. 